\title{
Maritime City: Using Games Technology to Train Social Workers - Some Initial Results
}

\author{
Ryan Flynn ${ }^{1}$, Lachlan McKinnon ${ }^{1}$, Elizabeth Bacon ${ }^{1}$, and Janet Webb ${ }^{2}$ \\ ${ }^{1}$ University of Greenwich, Maritime Campus, London, SE10 9LS, UK \\ ${ }^{2}$ University of Greenwich, Avery Hill Campus, Eltham, London, SE9 2PQ, UK \\ \{r.d.flynn, l.mackinnon, e.bacon, j.s.webb\} @greenwich.ac.uk
}

\begin{abstract}
Maritime City is an educational tool for training Healthcare professionals, currently targeted towards Social Workers. It has its roots in the serious games area and is developed in a commercial game engine. This paper presents some initial results from testing the game with in-practice Social Workers in the context of child protection, with the aim to show equivalence between this approach and more traditional methods. The testing found that the game was realistic (apart from in some areas, which has provided new directions for the research) and also showed that there are many areas of the game experience that impact on the learning in ways similar to that of traditional role-play.
\end{abstract}

Keywords: Games technology, health, social work, serious game.

\section{Introduction}

Games Technology has, over the past 20 years, become more and more popular for use in training and education. Examples range from the use of Brain Training style games in primary and secondary education in Scotland [1] through to the US military, which have invested heavily in games for training [2]. This paper aims to show how Maritime City can help with one aspect of training, that of preparing for situations that are unfamiliar.

In the Social Work field in the UK, there is a set of standards that define a Social Worker role - the National Occupational Standards for Social Work [3]. However, there is an issue with students having access to "real world" training scenarios. This is of such concern that the 2009 Social Work Task Force report identified it as one of the top three issues facing Social Work education in the UK, saying:

"Practice Placements: that new arrangements be put in place to provide sufficient high quality practice placements, which are properly supervised and assessed, for all social work students." [4]

This makes a very clear statement to educators in this field - you must make sure that your students all get some form of placement to help them prepare for real life practice. As this is not always possible, a popular and widely used alternative to some placement activities is role-play. However, role-play has some drawbacks, a point made by Woodhouse: 
"McHardy and Allan...have reported that 44\% of students have negative feelings about the use of role play, with a further 29\% 'sitting on the fence'..." [5]

Although a small example, this shows that students have some resistance to roleplay; furthermore, Woodhouse raises other issues with role-play including safety and the danger of the activity going off course and becoming unfocused.

\subsection{Maritime City}

Maritime City is a training environment built using games technology that aims to help solve some of these issues.

The game is designed using the Source game engine, created by Valve Corporation [6]. This was chosen as it has excellent facial animation features which is important as Dolgoff et al mention when discussing the imposition of values when Social Workers deal with clients:

"Covert messages about value, such as body language, facial expressions, and tone of voice, are often more powerful than overt ones" [7]

The ability to read these emotional states is, as Dolgoff et al. mention, crucial for anyone training to be a Social Worker. They need to understand the state of their client but also reflect on their practice in order to improve their own communication skills in both verbal and non-verbal forms.

\subsection{Scenario Overview}

The first scenario developed in Maritime City is loosely based on the Baby Peter Connelly (Baby P) case. In this particular case, the child was deemed at risk but was not removed from the situation [8]. This resulted in the child continuing to be abused and eventually resulted in the child's death.

In the game, the player takes control of a Social Worker named Brendan. He has been asked to investigate a disturbance at a local house where there is a lady called Elli living with her two young children, Tara and Liam.

The scenario is designed to mirror the pertinent aspects of the Baby $\mathrm{P}$ case and encourage the player to reflect on their practice. The game encourages players to investigate a range of approaches for each part of the scenario.

\section{The Experiment}

The game was tested with a group $(n=10)$ of in-practice (i.e. qualified, practicing Social Workers) as part of a child protection module being studied as part of a Masters degree. They were asked to play the game and then complete a role-play, both on the same scenario.

The experiment was designed to ensure that none of the class were unfairly advantaged or disadvantaged by undertaking the experiment. All members were fully informed of their rights and responsibilities and were free to leave at any time.

The surveys were designed to have a balance of Open-ended and Likert-scale (using a higher-is-better scale) questions in order to provide a variety of data. 
The general purpose of the experiment is to test whether it is possible to show equivalence between educational games such as Maritime City and more traditional teaching methods such as role-play.

\section{Results}

Results based on the post-game survey had a number of interesting findings. The first question asked the player to rate how realistic they found the characters; a majority (37.5\%) answered "Very realistic".

The next question asked players how easy they found the game to use (the player moves with the keyboard and "looks" with the mouse). The majority of the responses said that they found it easy to use but there were $37.5 \%$ of responses saying that they did not find it easy to use.

The players also felt that the game was successful at communicating the lesson content, with $62.5 \%$ of respondents rating it "Quite effective" (the second highest option).

The free text options gave more detail to the situation. When asked how they would approach the situation if they had to do it again, respondents wanted a joint visit $(n=2)$, to call the Police $(n=2)$, or to use different language and tone of voice $(n=2)$. When asked which things they thought Brendan did well, there were common themes of risk assessment $(n=4)$, the choice of questions $(n=3)$ and the fact he decided to call for assistance $(n=3)$. All of these are vital jumping-off points for discussion and tie directly into the underlying learning areas for the session.

Another element that threw up some surprising results regarded the question on what risks the player identified from the scenario. The reason this is surprising is because the scenario was never designed to have overt risks, but the players identified a lot more than just the obvious ones in the game (e.g. broken bottles). For instance, some respondents $(n=2)$ pointed out that Luke was either drunk or under the influence of narcotics, despite this never being mentioned in the speech in the game. This shows that the character behavior alone is enough to communicate some traits.

Finally, when asked to provide feedback on the game generally, there were a number of responses that revolved around a very specific area on the realism of the environment and characters - the cleanliness and state of the environment and characters. The house was deemed to be too tidy, too well kept, not realistic enough from the outside (the brickwork was too clean and the garden too well maintained). The characters themselves were also criticized for being too clean and well kept, something that the players felt was not a true reflection of what they see in practice.

\section{Conclusions}

Maritime City has only been used in small-scale tests so far but the initial results from these tests are pleasing. The scenario given for people to use has got good feedback and there are a number of issues raised by the testing group that have direct implications for development of the product. 
The most interesting thing, however, has been the realization that Maritime City can bring about the same areas of discussion as, say, a role-play session. The areas students identified that they wished to discuss further after playing the game (such as the risk factors for the characters, or the environment) was something that was hoped would occur. Although a small testing group it appears it would be possible to use games such as Maritime City to foster debate around issues in much the same way as role-play does currently. Obviously, there needs to be a lot more testing and further analysis of the results to help fully substantiate this claim but it is a good starting point.

\section{References}

1. BBC. Scottish education secretary backs 'brain training'. (December 26, 2009), BBC News: http://news.bbc.co.uk/1/hi/8430768.stm (retrieved November 8, 2010)

2. Atkinson-Bonasio, A.: (August 29, 2008),

http: / /www.modelbenders.com/papers/RSmith_Escapist_080829.pdf (retrieved November 8, 2010)

3. Department of Health. Requirements for Social Work Training (June 2002), http: / / www.dh.gov.uk/prod_consum_dh/groups/dh_digitalassets/d h/en/documents/digitalasset/dh_4060262.pdf (retrieved November 8, 2010)

4. Social Work Task Force (November 2009),

http: / / publications. education.gov.uk/eOrderingDownload/011142009DOM-EN.pdf (retrieved November 8, 2010)

5. Woodhouse, J.: Role-play: A Stage of Learning, http://www.radcliffeoxford.com/books/samplechapter/0061/Woodhouse_chp86932e500rdz.pdf (retrieved April 22, 2011)

6. Valve Corporation, SOURCE (2007), http://source.valvesoftware.com/ (retrieved April 21, 2011)

7. Dolgoff, R., Loewenberg, F.M., Harrington, D.: Ethical Decisions for Social Work Practice. Cengage Learning (2008)

8. CommuityCare.co.uk. Baby Peter case in Haringey. CommunityCare.co.uk (December 09, 2010), http: / / www. communitycare.co.uk/Articles/2010/12/09/ 109961 /baby-peter-case-in-haringey.htm (retrieved April 21, 2011) 